Pedagogía y Saberes No. 51

Universidad Pedagógica Nacional

Facultad de Educación. 2019. pp. 133-144

\title{
Problematizar lo humano en educación. La dimensión política y el concepto de pensamiento crítico en la pedagogía de Freire y Giroux
}

Artículo de reflexión

Problematize the Human Condition in Education. The Political Dimension and the Concept of Critical Thinking in the Pedagogy of Freire and Giroux

Problematizar o humano na educação. A dimensão política e o conceito de pensamento crítico na pedagogia de Freire e Giroux

Yesid Niño Arteaga*

Para citar este artículo:

Niño, Y. (2019). Problematizar lo humano en educación. La dimensión política y el concepto de pensamiento crítico en la pedagogía de Freire y Giroux. Pedagogía y Saberes, 51, 133-144.

Profesor de la Universidad de Nariño. Magister en Ciencias Humanas de la Universidad de Nariño e investigador del Grupo Historia, educación y desarrollo (HISED).

Correo electrónico: yesidnio@hotmail.com

Código ORCID: 0000-0002-5628-8854. 


\title{
Resumen
}

Este artículo de reflexión propone la lectura de algunos postulados de la Pedagogía crítica y sus aportes al contexto educativo a partir de las investigaciones de Paulo Freire y Henry Giroux. Se destaca la reflexión de ambos autores sobre el vínculo existente entre política y educación y la importancia de desarrollar pensamiento crítico. El texto intenta mostrar que la constante indagación sobre lo humano puede representar un elemento desequilibrante del orden neoliberal, a través de un debate sobre lo humano según el criterio de adaptación expuesto en el neoliberalismo y que es cuestionado por la Pedagogía crítica. Se hace una aproximación a la dimensión política en educación propuesta por Freire y luego desde la crítica cultural de Giroux con énfasis en sus aportes al concepto de pensamiento crítico y al sentido del docente como intelectual. Por último, se discute el papel de la educación frente a la creciente burocratización de lo humano en el siglo XxI.

\section{Palabras clave}

educación; formación política; filosofía de la educación; pedagogía crítica; pensamiento crítico

\begin{abstract}
This reflection article proposes a reading of some concepts of Critical pedagogy and its contributions to the educational context from the pedagogic research of Paulo Freire and Henry Giroux. It highlights both scholar reflection about the relationship between politics and education, and the importance of developing critical thinking. The article tries to show that the constant inquiry into the human can represent an unbalancing element of the neoliberal order, by means of a debate on the human is presented according to the criterion of adaptation exposed in neoliberalism and that is put in question by the Critical pedagogy. An approach is made to the political dimension in education proposed by Freire and then from the cultural critique of Giroux with emphasis on his contributions to the concept of critical thinking and the teacher's sense as an intellectual. Finally, the article discusses the role of education about the growing bureaucratization of the human condition in the XXI century.
\end{abstract}

\section{Key words}

education; political education; philosophy of education; critical pedagogy; critical thinking

\section{Resumo}

Este artigo de reflexão propõe uma leitura de alguns postulados da Pedagogia crítica e suas contribuições para ao contexto educacional a partir das pesquisas de Paulo Freire e Henry Giroux. Argumenta-se no artigo a reflexão dos autores sobre a relação entre política e educação, assim como a importância de desenvolver o pensamento crítico. 0 texto tenta mostrar que a investigação constante do humano é um elemento desequilibrador da ordem neoliberal, a partir do debate sobre o humano apresenta-se o critério de adaptação exposto no neoliberalismo e que é questionado pela Pedagogia crítica. A dimensão política na educação proposta por Freire é abordada, seguida da crítica cultural de Giroux com ênfase em suas contribuições para o conceito de pensamento crítico e o sentido do professor como intelectual. Finalmente o artigo analisa o papel da educação na crescente burocratização do ser humano no século XXI.

\section{Palavras chave}

educação; educação política; filosofia da educação; pedagogia crítica; pensamento crítico 


\section{Introducción}

La educación se define en la tradición pedagógica desde los términos educere y bildung. El primero "alude al desarrollo de un ser vivo basado en el despliegue de las potencialidades vitales que se generan en la naturaleza" (Cánovas, 2014, p. 179). En el segundo término se sugiere que la "educación equivale a una obra de la cultura" (p. 179). En lo transcurrido del siglo XxI el capitalismo hegemónico parece apuntar al proyecto de una educación hecha para adaptar a la "juventud desechable" al horizonte del neoliberalismo, para formar su dimensión ética y política a partir de lo funcional como futuros administradores y gregarios de las políticas neoliberales (Robbins, 2012). Ante esa problemática, varios investigadores han indagado acerca de una probable vigencia de la actividad crítica en el campo pedagógico y educativo latinoamericano (Cánovas, 2014; Giroux, 2004, 2013, 2017, 2018; Lorente, 2012; Montes y Mendoza, 2018; Ortega, 2009; Ospina y Ramírez, 2016; Piatti, 2008; Saltman, 2012). ; Una aproximación a las ideas de la Pedagogía crítica remite a hacer más compleja la educación como "una teoría del conocimiento puesta en práctica, un acto político y un acto estético" (Freire, 2015, p. 65).

Por eso el artículo plantea un análisis en una perspectiva antropológico-filosófica hacia el hecho educativo, a partir del trabajo hermenéutico que permita al lector identificar relaciones entre la actitud crítica — denominada así por Horkheimer (2003) — que vincula la actividad intelectual con la indagación los sentidos de lo humano dentro de una posible trasformación social, con las ideas de pedagogos del continente americano como Paulo Freire y Henry Giroux, quienes son considerados junto a otros autores como iniciadores de la Pedagogía crítica. Con la revisión bibliográfica, además del objetivo anterior, se apunta a la construcción de reflexiones en el ámbito de lo educativo, a partir de la crítica a la concepción y proyección en lo social del neoliberalismo.

Con esto se pretende consolidar un pequeño aporte al estudio de las corrientes pedagógicas contemporáneas en busca de no dejar inacabada la reflexión sobre el papel de la Pedagogía crítica y su posible vigencia para la educación del presente siglo. No obstante, se reconoce que el artículo explora la realidad de la educación desde una visión filosófica, para declarar que el terreno de la teoría educativa debe reexaminarse de manera constante y sin duda serían valiosas nuevas investigaciones de carácter didáctico, sociológico y epistemológico que continúen con este comienzo el cual invita a que las investigaciones se apoyen en la consolidación de una actividad crítico-práctica.

Hay quienes sostienen que el discurso de la Pedagogía crítica tan solo remite a desacuerdos con el sistema político vigente, a impulsar la tensión entre docentes, escuela y Estado, a frívolas detracciones sobre el currículo, sobre la dimensión instrumental, sobre el modelo conductista; o que los pensadores de esta corriente pedagógica usan la teoría para crearse la imagen egocéntrica o arrogante de "heraldos de la democracia", "clarividentes", de promover el mesianismo o el quiliasmo en las escuelas (Rochester, 2003); de censurar o menospreciar subjetividades políticas, religiosas, adultocéntricas o de ir en contra de otro individuo que está sitiado en el discurso neoliberal. Los ejemplos de polémica y detracción del discurso neoliberal hacia la Pedagogía crítica parecen acentuarse contra la dimensión subjetiva de sus autores, en cómo presentan sus escritos, en cómo publican, cruzan, reflejan o comparten sus ideas con otros autores de la misma corriente, en el por qué usan todavía el discurso "rancio" y "devaluado" del marxismo o el discurso "borroso", "aireado" o "abstracto" del posmodernismo (Rochester, 2003).

Ante esas afirmaciones se lanza la invitación a comprender antes que la crítica no puede ser neutral (Freire y Faundez, 2018), puesto que la posibilidad de lucha y la afirmación de lo no idéntico son aspectos fundamentales del pensamiento (Habermas, 1994; Marcuse, 2016), la base primordial de la conciencia humana y de una posible praxis social.

Dussel (2016) sostiene que el acceso a la realidad es siempre mundano, es decir, lingüístico, histórico y cultural. Para la Pedagogía crítica la realidad educativa debe ser entendida como realidad social que permite abordar lo no idéntico del pensamiento $\mathrm{y}$ de la realidad. Por tanto, el hecho educativo como parte de la realidad concreta del ser humano debe dar proximidad al debate, a la creación, al reconocimiento de las diferencias, a la poiesis y al pensamiento crítico que logra posicionar lo humano en su carácter palabreado, dialógico, radical.

El proyecto educativo del neoliberalismo tiende al error al confundir la noción de libertad con libertad de adquisición. Para el neoliberalismo la libertad consiste en poder elegir y comprar en el mercado aquello que se desea (Dussel, 2016). El poder de elegir implícito en la experiencia de libertad se confunde con el poder del consumo derivado de la pseudolibertad o gratificación de poseer poder económico para corresponder a la realidad mercantilizada. El 
constructo teórico de quienes defienden una educación neoliberal se nutre de una pseudoconcreción que confunde la actitud crítica (Verhalten) ${ }^{1}$ con el fetichismo de la asimilación acrítica de un discurso rotulado (Überschrift).

El debate se amplía cuando se observa que la perspectiva social del Estado sobre educación, en el caso de las leyes fundamentales del Estado colombiano para suministrar un importante ejemplo para Latinoamérica (Ley 115, 1994; MEN, 2006), no mencionan la relación directa entre mercado y educación, entre sector empresarial y hecho educativo. Todo lo contrario, en el artículo $1^{\circ}$ de la Ley 115 de 1994 se enuncia: "la educación es un proceso de formación permanente, personal, cultural y social que se fundamenta en una concepción integral de la persona humana, de su dignidad, de sus derechos y de sus deberes". De ningún modo esta concepción de la educación se deslinda del conocimiento y del aprendizaje sobre lo humano, para en su lugar enfocarse en priorizar el desempeño según las necesidades del sector empresarial y/o productivo como lo reconoce la educación neoliberal (González y Rosas, 2016). De hecho, los fines de la concepción educativa propuesta por el Estado colombiano pueden ser considerados como la parte esencial del deber, pero también del impulso utópico que busca favorecer el mejoramiento de la educación:

La formación en el respeto a la vida y a los demás derechos humanos, a la paz, a los principios democráticos, de convivencia, pluralismo, justicia, solidaridad y equidad, así como en el ejercicio de la tolerancia y de la libertad. (Ley 115, 1994, art. 5).

Nada más extraviado que el negar con necedad el tacto, el afecto o la intersubjetividad propia de la educación creyendo que algún discurso pueda reproducir la realidad de manera exacta o inequívoca. No puede haber un marco político correcto si la corrupción de lo humano permanece creciente y evidente. Dentro de los intereses del Estado está mejorar la calidad de la educación, pero implícitamente esto lleva también a mejorar la democracia. La cuestión radica en cómo corresponder a esta intencionalidad de bienestar social que, en general, tiende a no ser cumplida. Si bien en Colombia la Ley General de Educación de 1994 apunta a consolidar un estado social de derecho desde el contexto de la educación básica y secundaria, esto también suscitó el interés de la élite hegemónica por implementar el proyecto de adaptación neoliberal.

1 Designada así por Horkheimer (2003) para diferenciar la propuesta de una Teoría crítica de actitudes pasivas y neutrales de la crítica cientificista tradicional heredada del siglo XIX.
De allí que el artículo presente una aproximación a la postura ético-política de la Pedagogía crítica sostenida por Freire y Giroux, quienes enseñan que ante la falta de políticas que garanticen verdadera calidad educativa - pero también ante el escenario pedagógico y curricular que no da lugar a un único sustento epistemológico- se debe otorgar importancia a la búsqueda constante de sentidos del devenir humano y social antes que al atento desarrollo del sector productivo.

Dussel (2016) comparte la idea de que ante la injusticia se debe hacer crítica para que luego se posibilite la constitución social de la ética; pero si la injusticia del sistema económico definido por el capital tiende a invisibilizar la corrupción y la misma injusticia, solo se puede avenir una crítica que indague de modo directo acerca de la exterioridad negada para los oprimidos. El Otro en su alteridad pone en tela de juicio el proyecto de adaptación neoliberal.

\section{La pedagogía crítica frente al error de una educación apolítica}

Una de las ideas más relevantes de Paulo Freire ${ }^{2}$ es que la educación posee un marcado carácter político. El pensamiento freiriano desde La educación como práctica de la libertad y La pedagogía del oprimido enfatiza que los seres humanos tienen la posibilidad de describir y transformar la realidad, puesto que la realidad se funda en la medida en que se pueda hablar de ella, en que se posibilite su descripción (Freire, 1980, 2002; Freire y Faundez, 2018). Cuando se asume que la educación y la ciencia deben ser neutrales o se pretende negar su politicidad, según Freire, se está asumiendo también un determinado carácter político.

Un acto político implica tanto afirmar la politicidad como negarla, de allí que una educación neutral, o más bien apolítica, sea considerada por Freire como una falacia que busca diseñar cierta dimensión política desde la ideología dominante (Freire y Faundez, 2018). Para comprender lo anterior, es válido afirmar antes que para el pensamiento freiriano la ideología es algo concreto, puesto que son ideas-acción que adquieren fuerza y constituyen formas de poder dentro del ámbito de lo cotidiano (Freire y Faundez, 2018). De allí que una ideología resulte como

Sobre el pensamiento de este importante pedagogo y filósofo latinoamericano se han escrito variadas investigaciones en cuanto a su vida y obra, si el lector lo considera pertinente, se recomienda una aproximación a los estudios de su visión ética y política en Patriani (2002), Martín-Baró (2002), Hernández (1990) y Almeida (2002). 
dominante en la medida en que pueda ejercer mayor poder de dominio sobre el mundo de la cotidianidad social y singular de los individuos. No en vano Freire se detiene a analizar el plano antropológico y político que se configura en la educación y propone que el ser humano es mucho más que un cliente-consumidor.

Una tarea concreta de la existencia humana es desarrollar actitudes críticas. Para Freire (2002) la captación de la realidad, de los datos objetivos que se unen a otros datos y hechos de la realidad, es crítica y reflexiva por naturaleza. Si el ser humano debe participar de la construcción histórica de su época, tiene que empezar por asumir que su desarrollo como sujeto se encuentra en gran medida dominado por la fuerza de la "publicidad organizada", por su ideología, que inhibe al ser humano de su capacidad de decidir y lo convierte en objeto hasta su cosificación (Freire, 2002). La categoría de lo humano en el neoliberalismo se equipara a mercancía: recurso o material humano cuyo desafío ontológico es asimilar los retos de la globalización y el mundo del mercado (Slaughter y Leslie, 1997). Es decir, que se rebaja a puro objeto disfrazado de iniciativa y optimismo que asimila el proyecto de adaptación. De allí que en el neoliberalismo se propague, bajo la pasividad y el confort de una cultura del negocio, del espectáculo y de un creciente "capitalismo académico", la desintegración entre el trabajo y el pensar, que hace que el ser humano se adapte a los propósitos de la libertad de mercado y adopte un yo que no le pertenece, bajo el supuesto de una pseudolibertad de poder elegir un objeto y adaptarse a los fines de un discurso muchas veces autoritario.

Es viable reflexionar sobre uno de los puntos de crítica de la pedagogía de Freire que él denominó como la "educación bancaria" la cual se cultiva por medio de una "pedagogía del capital" (Freire, 1980, 2009, 2015), que despliega el interés del mercado por silenciar la "curiosidad epistemológica" de los estudiantes, y abolir una posible pedagogía de la pregunta para consolidar una pedagogía de las respuestas a preguntas inexistentes (Freire y Faundez, 2018). El proyecto de adaptación del neoliberalismo plantea un devenir pasivo porque en él el ser humano no tiene las herramientas para alterar $s u$ realidad ni la realidad del mundo de la vida. Tan solo concede al ser humano fuerzas pasivas, caracterizadas por permanecer a la defensiva. A partir de la pedagogía vivenciada por Freire se hace válido interrogarse, pero también el seguir buscando alternativas, ante los crueles panoramas producidos por el capitalismo en la actualidad, como sistema defendido por las élites que controlan el poder económico-político. Con base en esto se lanzan preguntas como: ¿Qué sentidos y posibilidades de vida y de pensamiento crítico se trazan en la educación actual? ¿Cuál es la idea de ser humano que subyace en lo educativo y, por ende, en lo político? ¿El maestro es consciente de la dimensión política que marca el hecho educativo?

Estos interrogantes se pueden vincular al análisis antropológico-filosófico de la educación desde algunos postulados de la Teoría crítica, a partir de los cuales se buscan establecer perspectivas diferenciales o rupturas con el modelo capitalista. Así lo enseña Horkheimer: el pensamiento en realidad es una praxis, no es posible desvincular el pensar y el actuar, la transformación social dependerá del devenir de un comportamiento crítico (Horkheimer, 2003). Bajo ese antecedente ya se advierte que los postulados de la Teoría crítica se pueden relacionar con la perspectiva pedagógica de la Pedagogía crítica.

Otro pensador de la Teoría crítica como Marcuse llega a justificar la validez de la lucha del ser humano ante la dominación totalitaria y la falta de libertad, resultante de la desequilibrada tendencia a la acumulación y el consumo en la que gira el aparato ideológico capitalista (Marcuse, 2016). Una manipulación de las necesidades humanas que sin duda se vivencia en la actual crisis de la ideología neoliberal, donde la adaptación al consumo, la plétora de información y la diversión, antes que la crítica, son espejismos que parecen arrastrar la esencia del problema. ${ }^{3}$

Para la Pedagogía crítica los educadores deben abordar cuestiones sociales colectivas, es decir, las problemáticas humanas, para lograr la defensa de la educación pública y posibilitar así la democracia radical, cuyo despliegue es la base para dignificar el acto educativo dentro de la noción de libertad humana y no libertad de mercado, puesto que lo "radical" busca afirmar prácticas de conocimiento crítico ligadas a la posibilidad de cambio social y democrático, donde docentes y estudiantes puedan reconocer la ambivalencia y la incertidumbre como dimensiones fundamentales del aprendizaje. Y para eso docentes y estudiantes necesitan un nuevo lenguaje político y pedagógico que despliegue la crítica sobre el sentido de lo humano en la actualidad de la escuela, pero también en la vida cotidiana, para abordar los versátiles contextos sociales y desarrollar formas de pedagogía crítica capaces de desafiar al neoliberalismo y a otras tradiciones antidemocráticas acentuadas en el siglo XXI (Giroux, 2013).

3 Según el filósofo Byung Chul Han el neoliberalismo se erige en el nuevo orden de la autoexplotación y la autoproducción ilimitada que se fundamenta en la lógica proveniente de "la dictadura del capital", a través de proporcionar la ilusión "de una rápida experiencia exitosa y de un sistema de gratificación instantánea" (Han, 2015, p. 77), cuyo fin es el aumento del rendimiento y la optimización del valor del producto. 
Dentro del despliegue de la intersubjetividad la democracia radical se sitúa en el entramado de lo humano como una apertura al Otro: los jóvenes, las mujeres, los trabajadores, las comunidades indígenas, afrodescendientes, raizales, alternativas; a los colectivos sociales, a la defensa de la vida natural y animal, a las reales necesidades de los pobres y no tanto de las élites que ostentan el poder y dictaminan definiciones humanas desde lo burocrático para extender su permanencia en lo mismo. Por eso no se puede deslindar del acto educativo la politización y la posibilidad de conformar otra cultura política, puesto que luchar por el mejoramiento educativo es luchar por el mejoramiento democrático. De allí que Giroux indague de forma directa en los problemas de la realidad y otorgue sentido a la democracia radical que se presencia en el papel del docente:

What might it mean for educators to take seriously the notion that democracy should be a way of thinking about education one that thrives on connecting equity to excellence, learning to ethics, and agency to the imperatives of social responsibility and the public good. (Giroux, 2017, p. 25).

Para Giroux los educadores deben tomarse en serio el vínculo entre educación y democracia, nunca desligarse de la correspondencia del hecho educativo con la ética, la política y la defensa de lo público. En ese sentido y en contravía del neoliberalismo, no es posible abogar, ni de manera teórica ni práctica, por una disociación de la educación con la dimensión política y antropológica de la realidad social.

La actitud crítica (Verhalten) comparte el propósito en lo educativo de posibilitar trasformaciones sociales y permitir otro sentido en la formación humana. Por eso se hace válido mencionar que ciertos autores de la Teoría crítica como Horkheimer, Marcuse, Habermas, Adorno, por citar a algunos autores cuyas ideas se tratarán en el artículo, son una referencia ineludible para lo que se entrevé como un cimiento epistemológico de la Pedagogía crítica.

La vigencia del pensamiento de Freire para la educación actual se acentúa en el siglo XXI, su visión de la pedagogía aproxima esta disciplina a la apertura del pensamiento popular, a la búsqueda de alternativas ante los innumerables problemas de las masas y no a los problemas de la élite. Plantea una indiscutible educación popular al afirmar en el hecho educativo la constitución de estructuras liberadoras para todos los seres humanos (Freire, 2015), desde el vínculo pensamiento-acción que gira en torno a problematizar la realidad, y que a su vez busca vigorizar los procesos de análisis del espacio educativo, pero al margen de la ideología dominante.
Esa relación entre pensar y actuar opuesta al principio que presupone al pensamiento como algo fijo o un "reino cerrado en sí mismo" (Horkheimer, 2003), y que en cambio desprende valores, palabras, diálogos, luchas y actitudes puede denominarse pensamiento crítico. De acuerdo con Dussel (2016), se entiende como la superación de la ingenuidad de la existencia que no afirma el cuestionamiento del mundo como posibilidad y apertura a la transformación histórica, y a la afirmación de otro sentido de lo humano. A su vez, este pensamiento se vincula al continuo aprendizaje sobre lo humano para que su formación y desarrollo tienda a deslindarse de la explotación, del consumismo, de la alienación, y en lugar de ello, anuncie dignidad, libertad y autonomía.

\section{El docente como intelectual}

Con las ideas de Henry Giroux ${ }^{4}$ se pueden viabilizar otras perspectivas teórico-prácticas en pedagogía para lograr comprender su correspondencia con lo político y el desarrollo de pensamiento crítico como parte del hecho educativo. A partir de su obra más conocida Los profesores como intelectuales: hacia una pedagogía crítica del aprendizaje (1990), se pueden formular importantes interpelaciones y relaciones con la actualidad educativa, a sabiendas de que no hay nada más actual para toda época que la actividad intelectual. Una aproximación a algunas de las ideas de Giroux se desprenden de tres interrogantes: ¿Cuál es el papel del maestro en la educación actual? ¿Conoce el maestro la dimensión política que afirma o niega en el acto educativo? ¿Responden las prácticas educativas al diseño económico-mercantil del hombre y del mundo propuesto por las ideologías dominantes, qué resistencias existen?

El filósofo Theodor Adorno advierte que después de las dos guerras mundiales la educación no puede considerarse un modelo pasivo de transmisión y formación humana (Adorno, 1998). Lo anterior se soporta en la pregunta: ¿Qué es lo humano, quién instaura su posible definición y cuál es su sentido en

4 Henry Giroux es uno de los pensadores de la Pedagogía crítica que ha configurado una considerable actividad investigativa la cual se encuentra expuesta en libros y artículos donde se compromete directamente con la posibilidad de cultivar el pensamiento crítico y de vincularse a la lucha por la transformación social (Giroux, 1990, 2003, 2017, 2018). Es importante resaltar que en su obra se abordan la pedagogía, la sociología, la filosofía de la educación, la crítica cultural y los estudios de juventud. Para una aproximación a su obra se recomienda la lectura de The Giroux Reader (Giroux y Robbins, 2006), libro que recopila gran parte de sus aportes en educación, donde se reconoce la vigencia de su pensamiento y su relevancia en los estudios sobre pedagogía y teoría curricular. 
la actualidad? Según el pensamiento de Giroux deben hacerse rupturas entre los fines de la educación y los entramados sociales que desde el siglo xx buscan consolidar la idea de lo humano desde disposiciones económicas. Para eso, los profesores en la actualidad tienen que formarse y desarrollarse como intelectuales transformativos (Giroux, 1990), para que se logre una respuesta a los desafíos de la educación y un enfrentamiento crítico con las posturas mercantilistas que ocultan la exploración de lo humano.

Montes y Mendoza (2018) ya advierten, al estudiar el escenario de la educación superior pública y privada en Colombia, que aún se intenta sostener la falsa conciencia de mantener el orden democrático e investigativo a través de extender la adaptación del ser humano a la lógica de mercado, sin propiciar impactos que puedan conducir a un progreso local ni social. Y vale agregar que si esta situación sucede en el ámbito de la formación de futuros profesionales, esto también tiende a ocurrir en todos los niveles donde se desenvuelvan laboralmente.

Lo anterior es un planteamiento que promueve la crítica sobre el trabajo profesional y sobre la naturaleza docente. Aunque Dewey ya había mencionado la figura del docente como intelectual, Giroux preserva la siguiente condición: las acciones del trabajo docente se desenvuelven con mayor vitalidad en un campo intelectual, no empresarial. La categoría intelectual representa una base teórica para examinar el trabajo de los docentes desde una lógica que no se funda en lo económico o en lo financiero (Giroux, 1990), y que debe sentirse como una posible salida ante la inminencia de la ideología dominante, la cual promulga una sutil adhesión al capitalismo que, según el autor, parece destinar la tarea de los docentes a procesos instrumentales o técnicos aislados de la dimensión política y antropológica de la educación.

Las prácticas educativas de los maestros comprometidos con la Pedagogía crítica consisten, de acuerdo con Giroux, en enseñar a los estudiantes de qué modo pueden traducir problemas singulares, de la familia, del barrio, de la ciudad, en reales problemáticas globales que precisan búsqueda de alternativas. Se promueve así el uso público de razón para desarrollar relaciones de reconocimiento, de valoración de las diferencias, de reciprocidad, de alcance crítico y creativo sobre el conocimiento humano. Para eso "se debe concientizar a los estudiantes acerca de las fuerzas ideológicas y estructurales que promueven el sufrimiento humano innecesario y a la vez hay que reconocer que se necesita más que concientización para resolver estas cuestiones" (Giroux, 2013, p. 17).
Según Giroux, en la época actual el neoliberalismo exterioriza el progreso personal como esencialvalioso, promueve una visión optimizadora de la realidad, lo que clausura la posibilidad para la lucha en común implícita en los posibles progresos sociales. Lo personal en su exageración neoliberal se convierte en pseudoconcreción moral y política y así se produce la devaluación del lenguaje de lo social (Giroux, 2013), donde la ideología dominante asume que las problemáticas sociales son formas patológicas o absurdas establecidas desde lo individual.

Ante esto se resalta la crítica del autor de Los profesores como intelectuales sobre la intención globalizadora de la ideología dominante, que es la de invisibilizar la crítica que se crea en el trabajo de los docentes y también se requiere para la afirmación de la vida. La actitud crítica es indispensable para la afirmación de la vida (Freire y Faundez, 2018). El ordenamiento y el control no son elementos de crítica sino elementos que provocan la crítica. Por eso las preguntas sobre el hecho educativo no se hacen esperar: ¿qué es una educación crítica? ¿Las pedagogías usadas por los docentes legitiman y reproducen ciertos intereses políticos y económicos?

Para Giroux (2003) la realidad educativa debe ser crítica y transformativa y eso implica tanto al ser humano como su devenir en el contexto sociocultural. No se trata de continuar con la separación del conocimiento y el poder, sino que se permita su compenetración con el mundo popular, con la gente del común, para que pueda salir de la mismidad capitalista y así participar de la construcción de su actualidad política; allí radica la principal forma de resistencia, ser capaz de atender y refutar cualquier discurso sin caer en la equivocación de la monopolización del conocimiento o en un conformismo cómplice con el desinterés frente a las problemáticas humanas.

A propósito, Giroux lanza una crítica cultural desde el plano educativo estadounidense que vale la pena mencionar: "Los jóvenes sufren bajo la tiranía de métodos que son formas de represión para disciplinar. Los docentes se encuentran sin poder y los administradores configuran sus escuelas como cárceles y llevan a sus estudiantes a la policía" (Giroux, 2018, p. 16).

Parece que la formación escolar tiende a definirse por la ideología dominante. Por eso Giroux se opone a la posición de quienes para él sostienen los principios neoliberales por medio de la defensa de la constante evaluación numérica y aumento del control del trabajo docente, para así generalizar y popularizar programas que aumenten el rendimiento, la vigilancia y la eficacia según criterios del sector productivo en el trabajo 
docente. Esto, según Giroux, aumenta el control sobre el desempeño de los docentes en procura de su corrección o sustitución, pero también deja de lado su papel como intelectual y constructor de la teoría educativa.

Los bienes públicos como las escuelas, según estos políticos y miembros de grupos de presión pertenecientes a las corporaciones, son inversiones financieras, consideradas como oportunidades de negocios. Para los multimillonarios que son antireformistas, los docentes, los estudiantes y los sindicatos simplemente se interponen en su camino y deben ser disciplinados. (Giroux, 2018, pp. 16-17).

Esa descripción de la realidad educativa parece "apocalíptica" para las formas actuales en las que se concibe, pero más bien es todo lo contrario, pues renueva y reconoce la crítica como una parte imprescindible de la actualidad educativa, que comienza en la exploración de las nuevas crisis que emergieron desde el siglo xx y parecen acentuarse en el presente siglo en la sociedad y en la escuela. Parte de lo anterior es reproducir en las escuelas "las injusticias de un sistema económico opresor" y en esa problemática se incluye comprender la enseñanza como gestión que aboga por una evaluación cuyo fin son resultados en términos numéricos lo cual, según Giroux, a su vez es una herramienta que admite el adormecimiento de las mentes y la destrucción del espíritu de los estudiantes (Giroux, 2018).

El error es que se problematiza la educación desde una lógica mercantilista que expande asimismo una lógica de la optimización y de la gratificación que se aparta del problema humano. Ante eso es válido pensar que el profesor intelectual es un profesor reflexivo, investigador, que presenta la dimensión política como imprescindible para el terreno de la educación, antes que una pedagogía basada en la gestión que reconoce al docente como un receptor pasivo comprometido con la efectividad (Giroux, 2003). La labor docente sostenida en lo intelectual permea el hecho educativo de la vinculación entre actividad humana y forma de pensamiento, para hacer del pensamiento crítico su eje y así una reinvención humana en la historia educativa. Un signo que entrevé cómo la Pedagogía crítica puede ir de la mano con la posibilidad de cambio y la transformación social.

Según la Pedagogía crítica, en la educación del siglo XXI se deben proporcionar las condiciones para que los estudiantes y los Otros reconozcan cómo usar el conocimiento que obtienen para criticar el mundo en el que viven y llegar a ser socialmente responsables para intervenir y posibilitar maneras más humanas para cambiarlo (Giroux, 2017).
Ahora bien, ¿es la Pedagogía crítica una alternativa epistemológica y metodológica dentro del que parece un eterno cultivo de un modelo pedagógico tradicional? La Pedagogía crítica permanece en el debate a través de la indagación en el papel del educador y de la escuela en un mundo que parece consumado por el capitalismo y su enfoque neoliberal, el cual tiende a glorificarse por encima de las crisis sociales. Giroux (1990) lanza su respuesta: se tiene que defender la propuesta del profesor como intelectual. Freire (1980) lo anunció antes: el maestro es quien se nutre de la posibilidad de una educación liberadora.

\section{La educación en el siglo XXI: resistir la burocratización}

Como se ha expuesto, un elemento en común en los planteamientos de Freire y Giroux (y que no sólo se conforma a partir de la generosa amistad que se dio entre ambos pedagogos), es la crítica que los autores despliegan ante la vinculación del plano educativo con el neoliberalismo y la burocratización. Así lo manifiesta Giroux desde su experiencia pedagógica: "Los estadounidenses viven un momento histórico que aniquila el pensamiento. Ahora la ignorancia otorga sentido de comunidad; el cerebro ha migrado a la arena del espectáculo; el único discurso que importa es el de los negocios" (Giroux, 2018, p. 15).

Si se analiza de forma crítica la anterior cita de Giroux, el mundo del espectáculo y de los negocios parecen conformar el horizonte de aspiraciones humanas dentro de la ideología dominante, por eso se consideran como componentes actuales del capitalismo financiero, teniendo en cuenta que en el presente siglo el capitalismo con sus modos de producción posindustriales no se ha trastocado en comunismo, como lo especulaba Marx, sino que ha mutado en neoliberalismo o capitalismo financiero donde se convierte al trabajador en empresario (Han, 2015).

Sin duda esto permite la propagación de la visión burocrática que se desglosa en dos aspectos: ser por medio de la tecnología accionada por la lógica mercantilista y presentar el criterio de lo humano dentro de la realización del poder económico. Freire define la burocratización como un proceso de adaptación que consigue arrebatar al ser humano su capacidad de asombro, su capacidad de preguntar, de crear riesgo, y, por tanto, que lo desalienta de usar su capacidad de crear, transformar y reinventarse (Freire y Faundez, 2018).

Las representaciones de lo humano formuladas por el neoliberalismo corresponden a un "sujeto de rendimiento explotador de sí mismo" (Han, 2015, 
p. 18), en las que surgen relaciones donde predomina el aumento del control, de la eficiencia, de la explotación del tiempo libre y del rendimiento, procurando una socialización que corresponde a la funcionalidad capitalista, que es la adquisición de cualquier finalidad en todo tipo de relaciones.

Si el humanizar está dentro de los posibles fines de la educación (Freire, 2009, 2015), se debe proponer un pensamiento crítico ante los valores neoliberales (la competencia, el emprendimiento, el funcionalismo que se orientan en la acumulación de capital), que elevan en exceso el desarrollo personal como deificación artificial de esa aparente nueva-libertad, que, en términos de Gramsci (2018), debe verse como una libertad fosilizada y dogmatizada la cual tiene como fondo su correspondencia con la esclavitud. Bajo la pretensión de explicar su novedad por medio de la correspondencia del pensamiento humano con la actual terminología económica (la globalización, el mercado con sus desafíos y sus intereses), instala esa lógica que se aparta de otros conceptos que pueden continuar la indagación de lo humano o de la sociedad.

Vale la pena indicar que lo anterior no se trata de ir en contra del aprendizaje propio de las ciencias y las artes, ni en contra del aprendizaje de las tablas de multiplicar o la enseñanza de la gramática o contra los conocimientos científicos básicos para las personas de cualquier sociedad, ni de una inútil "demagogia" que no permite el progreso, como muestra Rochester (2003). Quizás Gramsci (2018) tiene razón cuando afirma que en los países en que no se producen conflictos en la calle, en los que no se ve mancillar al Otro ni a las leyes fundamentales del Estado, ni se ve cómo domina la arbitrariedad, la ausencia de crítica o de lucha, el trabajo intelectual va perdiendo el espíritu revolucionario y se impone la "ley del mínimo esfuerzo" y el no hacer nada ante los problemas sociales se convierte en lo popular. En el caso de Colombia, por ejemplo, donde basta hablar con el vecino, sintonizar un noticiario o leer la primera página de cualquier periódico para darse cuenta de que los problemas descritos antes resultan evidentes, la Pedagogía crítica puede formular el desarrollo de un pensamiento crítico que provoque la reflexión ante los efectos contraproducentes de la pérdida misma de actividad crítica.

El concepto de humanizar la educación como parte del desarrollo de un pensamiento crítico se comprende como el poder orientarse a la defensa de la existencia humana, a la defensa de la existencia del mundo natural y a buscar alternativas a los problemas del mundo desde el mismo proceso de enseñanza y aprendizaje. Enseñar a pensar también es enseñar a resistir la burocratización basada en la manutención de las clases dominantes por medio del arduo trabajo de las masas, el aumento de las injusticias sociales y la perpetuación de la desigualdad. ${ }^{5}$ En síntesis, humanizar la educación del siglo XXI resulta en afirmar la defensa de una cultura de la vida que propicie una comprensión rigurosa del presente (Freire y Faundez, 2018).

Las prácticas educativas necesitan reinventarse de manera continua a partir de la comprensión del hecho que se hace política y arte cuando se forma a los estudiantes (Freire, 2015). Educar para lograr construir una cultura dentro de la diferencia capaz de liberarse de la dominación, capaz de filosofar, puesto que el filosofar se plantea como una virtud humana que conduce a la emancipación y propone la filosofía como elemento reflexivo de las actividades sociales (Habermas, 1994); de afirmar una actitud crítica (Verhalten) y comprender así que "el autoengaño colectivo solo se abrirá camino con la ausencia de un sistema educativo que ofrezca un espacio para el aprendizaje crítico y disidente, y que funcione como un laboratorio para la democracia" (Giroux, 2018, p. 19).

Los nuevos planteamientos en teoría educativa, con la Pedagogía crítica de Freire y Giroux, plantean vincular la educación del siglo XXI al progreso racional, al conocimiento popular, a la defensa ecológica, al pensamiento filosófico alternativo, a la "crítica radical", a una real participación política de las masas, teniendo en cuenta que ya Habermas cuestionó la pretensión que hasta Hegel presuponía para la actividad teórica y filosófica como reservada a las culturas desarrolladas o a poderosos sistemas gubernamentales a través de la expresión de una élite intelectual (Habermas, 1994).

Para la Pedagogía crítica las prácticas educativas deben "ayudar a los estudiantes a pensar críticamente acerca de cómo los acuerdos sociales, políticos y económicos existentes se podrían adaptar de mejor manera para abordar la promesa de una democracia radical como un objetivo" (Giroux, 2013, p. 19). En este punto el desarrollo de pensamiento crítico en las prácticas educativas es esencial para problematizar las teorías, las prácticas, la experiencia cotidiana, para construir preguntas de carácter inquebrantable y superar los dogmatismos mecanicistas que se apoderan del conocimiento humano (Freire, 2015). Además, para formar de manera integral de cara a la constante reinvención del mundo y lograr que

5 ¿Qué es lo humano en el mundo del oprimido, qué valor tiene lo humano en los contextos vulnerables? Son interrogantes que pueden ser pensados como posibles referentes acerca de la relevancia de la Pedagogía crítica, puesto que invitan a un llamado a la concienciación, a dejar de apartarse de la crítica frente a los problemas que aquejan al mundo y analizarlos a partir de la experiencia de clase de lo popular (Freire, 2002, 2009; Giroux, 2003). 
padres de familia, jóvenes, docentes y la comunidad trabajen por igual frente a la injusticia de la realidad económica y política. La educación del siglo XXI debe brindarles a los estudiantes "rupturas desconcertantes que muestren la energía feroz de la ira y la esperanza por un mundo mejor" (Giroux, 2018, p. 19).

Pensar también es resistir. Por eso la Pedagogía crítica logra advertir los desafíos que implican las definiciones de lo humano que se adentraron en el presente siglo y frente a las cuales corresponde afirmar el desarrollo de pensamiento crítico en todas las disciplinas del conocimiento humano como forma de resistencia. Freire enfatiza en los desafíos de la epistemología, política y pedagogía para el siglo XXI:

1. Superar la dependencia que el Norte ha impuesto en el Sur, "comenzar a surear para dejar de ser norteado". 2. Superar el hambre en el mundo. 3. Superar la violencia física y simbólica, el racismo, el sexismo y la correspondencia a los intereses económicos de las ideologías dominantes. 4. Enfrentarse a todo posible resurgimiento de "la amenaza fascista". 5. Revitalización del saber popular y alternativo. 6. Afirmar la importancia de la subjetividad en la posible transformación del mundo. (Freire, 2015)

\section{Conclusiones}

Ante las preguntas ¿cómo guiar la labor docente hacia una educación donde se trate la constante problematización de lo humano? ¿Cómo responder desde la educación a la actual crisis del hombre y del mundo? La respuesta de algunos es la continua actualización, control y tecnificación del trabajo docente. Mejorar en su inspección, procurar el aumento de rendimiento y la eficiencia para ciertos sectores, así como medios de intervención y reforma laboral para otros. Según lo expuesto en el artículo, esto tiende a formalizar una asimilación de la ideología dominante y la continuidad del neoliberalismo y su proyecto de adaptación basado en lo burocrático.

La crítica debe tener un punto de apoyo fuera del sistema para que ella misma tenga sentido. La esencia del pensamiento crítico es ir más allá de lo mismo desde la afirmación de una ética que procura tener proximidad con el rostro del Otro en su alteridad; que busca una relación de reconocimiento y de justicia con el pobre, el huérfano, el extranjero (Dussel, 2016).

Tanto Giroux como Freire hacen parte de la perspectiva crítica de la educación, puesto que ambos indagan en el enfoque burocrático que parece apropiarse del devenir del hombre en su realidad histórica suprimiéndolo de su actividad crítica. A su vez plantean una visión no conformista frente a la categoría de lo humano ni solidificada en cuanto al mundo político. Proponen un examen crítico dentro de la labor de los docentes de cara a una posible imposición del plano empresarial y/o productivo en el porvenir de lo humano. Freire reabre el campo de la pedagogía a su base, lo popular y el pensamiento crítico. Giroux defiende una posible apertura epistemológica que brinde a la teoría y a la práctica educativa creación propia, mediación y resistencia. Ambos le apuestan a los saberes populares, a la re-comprensión y reinvención de lo teórico y lo práctico integrado por las disímiles disciplinas del conocimiento que a su vez están presentes en la educación. Lo cual se ve como una posibilidad de interrelacionar el fulgor académico con la congruencia de una transformación social.

Este artículo invita a no dejar inacabada la reflexión sobre el papel de la actividad crítica y su posible validez en la educación del siglo xxI. Se insiste en que serían valiosas nuevas investigaciones que aborden la relación entre pensamiento crítico, juventud, contexto local-social, universidad y escuelas y, a su vez, se reitera la importancia de escrutar los nuevos desafíos que la teoría crítica necesita enfrentar, por ejemplo, los retos de la humanización en el actual contexto de desarrollo tecnológico y científico.

Para concluir, se invita a los lectores a continuar en la interpretación del amplio marco teórico de la Pedagogía crítica. El trabajo de Freire y Giroux sugiere la búsqueda de una orientación teórica que extienda la crítica en la metamorfosis de los sujetos hacia la conformación de un mundo más humano, en el que prime la creatividad y el pensamiento crítico, con una cultura política basada en conocimientos y valores. Una cultura que le permita a los ciudadanos indagar en los problemas sociales, en lugar de ocultarlos o extender el desinterés hacia la realidad concreta, considerando posible su participación en ese nuevo paradigma educativo en pro de posibles alternativas.

\section{Referencias}

Adorno, T. (1998). Educación para la emancipación. Madrid: Morata.

Almeida, M. (2002). Dimensiones del concepto de formación en Paulo Freire. Buenos Aires: Siglo XXI.

Cánovas, C. (2014). La perspectiva crítica en la educación: su vigencia en el contexto neoliberal. Revista Internacional de Educación para la Justicia Social (RIEJS), 3, 175-190.

Congreso de Colombia. (8 de febrero de 1994). Ley General de Educación. [Ley 115 de 1994]. Diario Oficial: 41.214. Recuperado de https://www.mineducacion. gov.co/1621/articles-85906_archivo_pdf.pdf 
Dussel, E. (2016). 14 tesis de ética hacia la esencia del pensamiento crítico. Madrid: Trotta.

Freire, P. (1980). Pedagogía del oprimido. Bogotá: Siglo XXI.

Freire, P. (2002). La educación como práctica de la libertad. Madrid: Siglo XxI.

Freire, P. (2009). Pedagogía de la autonomía: saberes necesarios para la práctica educativa. Buenos Aires: Siglo XXI.

Freire, P. (2015). Pedagogía de los sueños posibles. Buenos Aires: Siglo XXI.

Freire, P. y Faundez, A. (2018). Por una pedagogía de la pregunta. Buenos Aires: Siglo XXI.

Giroux, H. (1990). Los profesores como intelectuales: hacia una pedagogía crítica del aprendizaje. Barcelona: Paidós.

Giroux, H. (2003). Pedagogía y política de la esperanza. Teoría, cultura y enseñanza. Buenos Aires: Amorrortu.

Giroux, H. (2004). Public Pedagogy and the Politics of Neo-liberalism: Making the Political more Pedagogical. Policy Futures in Education, 2 (3), 494-503. Recuperado de http://www.cws.illinois.edu/iprhdigitalliteracies/ GirouxPublicPFinE2004.pdf

Giroux, H. (2013). La Pedagogía crítica en tiempos oscuros. Praxis Educativa, 2, 13-26. Recuperado de http://www. redalyc.org/articulo.oa?id=153129924002

Giroux, H. (2017). Rethinking Higher Education in a time of Tyranny? Revista Runae, 2, 13-29. Recuperado de http://runae.unae.edu.ec/revistas3/index.php/ RUNAE/article/view/38/46

Giroux, H. (2018). Por qué importan los docentes en tiempos oscuros. Revista de educación, 13, 13-19. Recuperado de https://fh.mdp.edu.ar/revistas/index.php/r_educ/ issue/view/149

Giroux, H. y Robbins, C. (Eds.). (2006). The Giroux Reader. Boulder: Paradigm Publishers.

González, C. y Rosas, D. (2016). Avances y retos en la formación para el trabajo en Colombia. Bogotá: BID.

Gramsci, A. (2018). Escritos. Antología. Madrid: Alianza.

Habermas, J. (1994). Sobre Nietzsche y otros ensayos. Madrid: Tecnos.

Han, B. (2015). Psicopolítica. Madrid: Herder.

Hernández, J. (1990). Pedagogía del ser: aspectos antropológicos y emancipatorios de la pedagogía de Paulo Freire. Zaragoza: Universidad de Zaragoza.

Horkheimer, M. (2003). Teoría crítica. Buenos Aires: Amorrortu.
Lorente, P. (2012). La evolución de la Teoría crítica. Reflexiones y digresiones sobre su vigencia para una educación crítica. Con-Ciencia Social, 16, 37-55.

Marcuse, H. (2016). El hombre unidimensional. Barcelona: Austral.

Martín-Baró, I. (2002). Psicología de la liberación. Madrid: Trotta.

Ministerio de Educación Nacional. (2006). Estándares básicos de competencias en lenguaje, matemáticas, ciencias y ciudadanas. Bogotá: MEN.

Montes, I. C. y Mendoza, P. (2018). Docencia e investigación en Colombia desde la perspectiva del capitalismo académico. Archivos Analíticos de Políticas Educativas, 26 (40). Recuperado de http://dx.doi.org/10.14507/ epaa.26.3220

Ortega, P. (2009). La Pedagogía crítica: reflexiones en torno a sus prácticas y sus desafíos. Revista Pedagogía y Saberes, 31, 26-33.

Ospina, H. y Ramírez, C. (2016). (comp). Pedagogía crítica latinoamericana y género. Bogotá: Siglo del Hombre.

Patriani, V. (2002). Una mirada semiótica sobre Paulo Freire. Buenos Aires: Siglo XXI.

Piatti, C. (2008). La enseñanza de la ciencia como necesidad de supervivencia: reflexiones hacia una pedagogía crítica de la sustentabilidad. En M. Gadotti, M. Gómez, J. Mafra, A. Fernández de Alencar (comps.), Paulo Freire. Contribuciones para la pedagogía (pp. 293-311). Buenos Aires: Clacso. Recuperado de http://bibliotecavirtual. clacso.org.ar/ar/libros/campus/freire/28Piatti.pdf

Robbins, C. (2012). Disposable Youth/Damaged Democracy: youth, neoliberalism, and the promise of pedagogy in the work of Henry Giroux. Policy Futures in Education, 6, 627-641. Recuperado de http://journals.sagepub.com/ doi/10.2304/pfie.2012.10.6.627

Rochester, J. (2003). Critical Demagogues. What happens when ideology and teaching mix. Education Next, 4, 77-82. Recuperado de https://educationnext.org/files/ ednext20034_77.pdf

Saltman, K. (2012). Why Henry Giroux's Democratic Pedagogy is Crucial for Confronting Failed Corporate School Reform and how Liberals like Ravitch and DarlingHammond are Making Things Worse. Policy Futures in Education, 6, 674-687. Recuperado de http://journals. sagepub.com/doi/10.2304/pfie.2012.10.6.674

Slaughter, F. y Leslie, L. (1997). Academic capitalism: politics, policies and the entrepreneurial university. Baltimore: Johns Hopkins. 